\title{
EDITORIAL
}

\section{LA INNOVACIÓN \\ EN LA UNIVERSIDAD DE CIENCIAS APLICADAS Y AMBIENTALES U.D.C.A}

\author{
Germán Anzola Montero \\ Rector
}

Las Universidades, históricamente, hemos cumplido con tres funciones sustantivas, que son la esencia del quehacer universitario de excelencia académica: la Docencia, la Investigación y la Proyección Social (nuestros vínculos con la sociedad).

Años atrás y, específicamente, en los tres últimos gobiernos, a las Universidades se les ha sumado o incorporado el concepto de INNOVACIÓN, como consecuencia del verdadero desarrollo científico y tecnológico del país. Esta realidad, nos lleva a pensar si todas estamos en condiciones de asumirla verdaderamente, como una responsabilidad adicional, a las ya indicadas: ¿Será que todas contamos con el perfil y los requisitos para conseguirla? Y, en particular, ċuna Institución con el nivel de desarrollo de la U.D.C.A?, ċserá ésta una nueva función o un factor adicional para diferenciar, aún más, a aquellas universidades que se dedican exclusivamente a la docencia o las se ocupan de la investigación y la extensión o las incluyen, además, la innovación? El rigor y la naturaleza de nuestros proyectos de investigación es lo que sí nos podrán comprometer con aplicaciones reales, que conduzcan a la respuesta y a la solución de problemas nacionales e, inclusive, globales.

Una primera reflexión que hacemos sobre el tema tiene que ver con cuestiones relativas, es decir, si los actuales proyectos de investigación -ciencia y tecnología- que venimos ejecutando apuntan a lograr un bienestar de la sociedad y a optimizar, sustancialmente, las condiciones económicas del país. Este es el verdadero sentido de lo que denominamos hoy "la economía del conocimiento", que es un desafío de la universidad colombiana de traducir los resultados de su investigación en un mejor vivir de la población. En ningún momento de nuestro desarrollo educativo ha sido tan prioritario invertir en el sistema universitario colombiano, pues ello significa involucrarnos en la construcción de la sociedad del conocimiento, igualmente, ser partícipes del verdadero impulso a la "Locomotora de la Innovación", que a puertas de finalizar el actual gobierno, se encuentra sin arrancar.
Una segunda reflexión hace referencia a que si la Innovación debe ser exclusiva responsabilidad de las universidades o si las demás Instituciones de Educación Superior están en capacidad de asumirla y ejecutarla, al igual que los sectores industriales, productivos e, incluso, las instancias del mismo sector público, que por su naturaleza así, lo determinen.

La tercera reflexión obedece a establecer a quién le corresponde financiar la innovación que se deriva del desarrollo científico y tecnológico. Incuestionablemente, el primer llamado a ello es COLCIENCIAS, máximo organismo responsable y promotor del desarrollo científico e investigativo de la Nación, que debe garantizar y propiciar el desarrollo armónico e integral para la generación del conocimiento, a partir de la definición de presupuestos reales y competitivos, frente a otras actividades del país. En consecuencia, es fundamental crear y fortalecer centros de excelencia, tanto del orden básico como aplicado, apoyar y consolidar las redes de reciente creación al igual que las ya existentes, estimular proyectos de investigación con componentes de cooperación interinstitucional, de carácter nacional e internacional, apoyar proyectos con componentes de significativo carácter regional e inter-regional y estimular y financiar proyectos, como Connect Bogotá-Región (actividades Universidad-Empresa-Estado).

El gran reto es el de transferir el conocimiento a la sociedad, integrarlo a la tecnología e innovación y colocarlo al servicio de la comunidad; es fusionarlo a la docencia y, en consecuencia, con la naturaleza del mismo, para aplicarlo para el "bien estar" de la sociedad.

En Colombia, se debe estimular la cooperación entre universidades privadas-públicas, privadas-privadas y públicaspúblicas, con miras a favorecer el crecimiento armónico del sistema universitario del país y, con ello, el fortalecimiento de la tecnología y de la ciencia; debe existir un sano equilibrio, en cuanto a la financiación de la investigación, en todas sus categorías, incluyendo, la INNOVACIÓN. 
Por otro lado, es necesario mantener una ecuanimidad entre la investigación básica y aplicada, debido a los altos niveles de inversión necesarios para la investigación básica y el desafío de vincular el conocimiento global a los problemas locales. Los sistemas de investigación actuales, se deben organizar con más flexibilidad, para promover la ciencia y la interdisciplinariedad, al servicio de la sociedad.

Todo lo anterior debe involucrar los resultados del estudio realizados por el Banco Mundial y la Organización para la Cooperación y el Desarrollo Económico OCDE, que propone seis estrategias para abordar el tema en consideración:

- Estimular la innovación en el sector productivo, apoyando a emprendedores e innovadores.

- Fortalecer el Sistema Nacional de Ciencia y Tecnología, mediante la creación de un fondo especial.

- Aumentar la capacidad del país en materia de investigación o innovación.

- Favorecer la difusión del conocimiento en los medios de comunicación.

- Concretar las inversiones públicas en sectores estratégicos.

- Fortalecer las regiones en materia de Ciencia y Tecnología, para incrementar su capacidad científica y tecnológica.
El propósito es que con estas estrategias, la inversión en Ciencia, en Tecnología y en Innovación, que hoy es de 0,47\% del Producto Interno Nacional, pueda crecer a un $2 \%$, en el 2019.

Es deber de la U.D.C.A, entonces, analizar los resultados de su investigación, hasta hoy, valorándolos frente a una apuesta con la innovación, pues entrar en este ámbito es algo que se debe hacer, a partir de un diagnóstico riguroso de las necesidades sociales, económicas, políticas, ambientales, en los cuales, podemos participar. Reconocer nuestra capacidad para generar conocimiento (en qué áreas del saber), como tomar decisiones estratégicas para aproximarnos a diferentes sectores, es decir, definir con prudencia todo aquello que ha de incorporarse, responsablemente, a nuestro proyecto educativo.

La U.D.C.A no debe ser ajena a estas reflexiones, por el contrario, debemos revisar y, de ser necesario, adoptar políticas que nos reafirmen en lo que estamos haciendo en el sector agropecuario, en recursos naturales, en ambiente, en salud y demás líneas de trabajo. Es así como podremos ser más competitivos y la condición para incorporarnos en los planes estratégicos, orientando nuestra visión con el futuro desarrollo tecnológico, desde la perspectiva de nuestras fortalezas institucionales y competir por espacios pertinentes, tanto de la investigación como de la innovación, requerida por la actual humanidad. 